ESTUDIOS 



\title{
EL ACTO ADMINISTRATIVO EXPROPIATORIO'
}

\author{
JOSÉ LUIS MARTÍNEZ LÓPEZ-MUÑIZ \\ Universidad de Valladolid \\ marlomu@der.uva.es
}

\author{
Cómo citar/Citation \\ Martínez López-Muñiz, J. L. (2018). \\ El acto administrativo expropiatorio. \\ Revista de Administración Pública, 206, 1 1-35. \\ doi: https://doi.org/10.18042/cepc/rap.206.01
}

\section{Resumen}

El texto vigente de la Ley de Expropiación Forzosa de 1954 no deja claro de forma expresa el momento en que tiene lugar el acto jurídico expropiatorio y admite diversas interpretaciones para su fijación. Dada su trascendencia, se considera pertinente determinarlo expresamente en la revisión de esta ley que ya se demuestra conveniente, situándolo en el llamado acuerdo de la necesidad de ocupación o en los actos de valor equivalente tan frecuentemente utilizados en nuestro sistema jurídicoadministrativo. Tanto en aquel como en estos han de garantizarse adecuadamente los derechos de participación en el procedimiento y de tutela judicial de los sujetos expropiables, en orden especialmente a la estimación del carácter indispensable para el fin de la expropiación, de los derechos e intereses a expropiar. La determinación y pago del justiprecio y la ocupación o toma de posesión de lo expropiado deben pasar a ser claramente procedimientos y actos de ejecución del acto expropiatorio.

1 Ha sido elaborado como homenaje al profesor Ángel Menéndez Rexach y se publicará también en el libro que se prepara en su honor con motivo de su jubilación como catedrático de Derecho Administrativo de la Universidad Autónoma de Madrid. Forma parte, además, del proyecto de investigación «Fundamentos de una codificación del derecho administrativo general básico español», DER 2015-66525-P (MINECO-FEDER). 


\title{
Palabras clave
}

Expropiación forzosa; acuerdo de necesidad de ocupación; garantías expropiatorias; contratos «forzosos»; título y modo en la adquisición de derechos patrimoniales.

\begin{abstract}
The current text of the Spanish Compulsory Expropriation Act of 1954 does not make expressly clear when exactly the compulsory expropriation order takes place. Different interpretations are possible. Due to its relevance, the future reform of the aforementioned Act, which seems to be highly convenient, should make clear that this compulsory order has to be identified with the specific resolution already required in the common procedure currently ruled by the law to define the rights to be taken, or with other acts of equivalent value so frequently used in the Spanish legaladministrative system. In both cases the law must ensure the rights of those whose properties could be taken, to participate in the administrative procedure required and to its judicial review, especially in order to determine in each case the indispensability of the rights and interests to be compulsorily taken, for the specific public purposes legally declared as legitimate target of expropriation. The further assessment and payment of the just price as well as the effective transfer of the expropriated rights must be then clearly regulated as procedures and acts of implementation of the expropriation previously ordered.
\end{abstract}

\section{Keywords}

Expropriation; compulsory purchase; eminent domain; ownership's guarantees; title and mode of acquisition of property rights. 


\section{SUMARIO}

I. INDETERMINACIÓN DE LA LEY DE 1954. II. INCIDENCIA DE LA CONSTITUCIÓN DE 1978. III. EL ACTO EXPROPIATORIO COMO «ACUERDO IMPERATIVO»DE «PRIVACIÓN SINGULAR». IV. EL ACTO EXPROPIATORIO DEBE IDENTIFICARSE MÁS PLENA Y COHERENTEMENTE CON EL ACUERDO DE NECESIDAD DE OCUPACIÓN DE LA LEY DE EXPROPIACIÓN. V. NATURALEZA ADMINISTRATIVA DEL ACTO EXPROPIATORIO. VI. IMPORTANCIA DE QUE LOS ACTOS EXPROPIATORIOS «IMPLÍCITOS» SE NORMALICEN COMO EXPLÍCITOS Y CON TODAS LAS DEBIDAS GARANTÍAS.

\section{INDETERMINACIÓN DE LA LEY DE 1954}

La Ley de Expropiación Forzosa de 16 de diciembre de 1954 es una de las pocas grandes leyes administrativas de los años cincuenta del pasado siglo que aún perdura como tal en nuestro sistema jurídico ${ }^{2}$ y que, desde su adopción, no ha dejado de recibir encomios por muchos de sus apreciables contenidos, aunque también resulta bastante obvia la necesidad de su revisión o incluso de su sustitución por un nuevo texto que la mejore y la actualice en cuanto resulte conveniente. En la legislatura 2000-2004 comenzó a trabajarse en ello en el Ministerio de Hacienda, pero no parece que llegara a proponerse oficialmente ningún texto. Claro que, a la vista de las nuevas leyes con las que se ha sustituido a algunas de nuestras más importantes leyes administrativas básicas en los últimos ańos, habría que recomendar no poca prudencia, para no venir a adoptar un texto que, en lugar de mejorar, empeore el que, bien que mal, viene rigiendo un ámbito tan importante del actuar de las administraciones públicas desde hace más de sesenta años.

Como ya apuntamos en su momento ${ }^{3}$, la Ley de Expropiación no configura con claridad el acto administrativo expropiatorio, el momento en

2 Así lo recuerda aún recientemente, por ejemplo, G. Fernández Farreres (2016), Sistema de Derecho Administrativo, II, 3 a ed. (págs. 245-246), Cizur Menor (Navarra): Civitas, Thomson-Reuters.

3 «Los sujetos de la expropiación», en VV. AA. (2003), La Ley de expropiación forzosa: análisis y perspectivas de reforma (págs. 59-61), Madrid: Ministerio de Hacienda. 
el que la Administración expropiante ejerce la potestad expropiatoria y la forma que haya de adoptar esa declaración de voluntad. Ningún precepto precisa cómo y cuándo se acuerda la expropiación forzosa por cualquiera de las entidades con competencia expropiatoria, a las que, en términos generales, alude el art. 2 de la Ley, obviamente cuando aún no existían las comunidades autónomas.

La regulación del procedimiento general expropiatorio - parte central de la Ley, concretada en su título II- contempla, como es bien sabido, un requisito previo capital, cual es la necesaria declaración de utilidad pública o interés social del fin a que haya de afectarse el objeto expropiado (art. 9), en el que trata de garantizarse una intervención legislativa para valorar y determinar los fines específicos que puedan justificar una expropiación; pero lo conforma luego, como tal procedimiento, con estas tres conocidas «fases»: el acuerdo de la necesidad de ocupación de bienes o de adquisición de derechos (cap. II del citado título II), la determinación del justiprecio (cap. III) y el pago y toma de posesión del objeto expropiado (cap. IV). Ninguna de las expresiones empleadas en el texto legal identifica en todo este procedimiento, sin embargo, cuál sea realmente el acto expropiatorio, ni determina en consecuencia el momento en el que la expropiación ha de considerarse adoptada, con independencia de la ejecución y consumación de sus efectos propios, vinculada sin duda a lo que la Ley denomina toma de posesión por el beneficiario del objeto expropiado.

El art. 32 del Fuero de los Espańoles, de 17 de julio de 1945 —incluido expresamente entre las Leyes Fundamentales a las que la Ley de Sucesión a la Jefatura del Estado de 1947 dio tal categoría con pretensiones de equivalencia a la Constitución del Reino, hasta que fueron expresa y nominalmente derogadas por la disposición derogatoria inserta en la Constitución española de 1978-, tenía establecido por entonces que nadie podrá ser expropiado sino [...] previa la correspondiente indemnización. Se había mantenido en este sentido lo que también ya había dispuesto, como recuerda el preámbulo de la propia Ley de Expropiación Forzosa, el art. 10 de la Constitución de 1876. Ya se decía lo mismo previamente en las Constituciones de 1837 y de 1845 , también en sus respectivos arts. 10. De distinto modo había exigido, sin embargo, la necesidad de previa indemnización el art.14 de la Constitución de 1869, porque se requería - y es muy de notar- como condición de la ejecución de la expropiación, pero no de esta misma, que en aquella Constitución habría de producirse en virtud de mandamiento judicial.

Cuando se redactó la Ley de 1954, por tanto, el principio o regla fundamental del previo pago o previa indemnización parecía impedir que pudiera producirse el acto expropiatorio sin que antes se hubiera abonado al expro- 
piado la correspondiente indemnización $n^{4}$, lo que abonaría la tesis de que la expropiación consistiría precisamente en el acto final de ocupación del objeto expropiado, solo posible en principio bajo esta ley - fuera del caso de urgencia, en el que, con todo, no deja de obligarse a un desembolso provisional previo (art. 52, 4a a $6^{\mathrm{a}}$ ) — tras el abono o la consignación o depósito legal del precio indemnizatorio. La expropiación, en suma, no se produciría en cuanto tal hasta el acta de ocupación a que se refiere el art. 53 de la Ley, que sería la que acreditaría formalmente el acto administrativo expropiatorio; un acto administrativo de naturaleza no declarativa sino real, cuyo contenido y efecto expropiatorio sería de suyo implícito o tácito, sin perjuicio de que en el acta pudiera además aludirse de manera explícita al carácter expropiatorio precisamente de la ocupación efectuada.

De todos modos, como venimos diciendo, nada decía la Ley de manera explícita al respecto. Y nada impedía tampoco hacer otra interpretación que entendiese que la regla fundamental del previo del pago de la indemnización referiría, en efecto, tal carácter previo a la consumación de la expropiación, no al acto jurídico que la decide, de modo que tanto las Constituciones de 1837, 1845 y 1876, como el Fuero de los Españoles de 1945, estarían hablando, a tal respecto, de la expropiación, queriendo significar la plenitud de su efecto propio, pero sin otras precisiones técnico-jurídicas. Es decir, estarían garantizando que a nadie se le puedan sustraer de manera efectiva sus bienes o derechos patrimoniales sino previo abono de su indemnización, además de por las causas y con los demás requisitos legales — principalmente de procedimiento- que esos textos constitucionales y la propia ley disponen. Con esta interpretación, evidentemente cabría diferenciar, como en general en la actuación administrativa, el acto administrativo propiamente expropiatorio y su ejecución o la consumación de sus efectos, con tal de que antes de esta última no dejase de indemnizarse debidamente al expropiado. Es lo que, como ya hemos señalado, llegó a explicitarse en el art. 14 de la Constitución del sexenio liberal democrático iniciado con la revolución de septiembre de 1868

Así venía a decirlo literalmente, en 1958, N. Rodríguez Moro, voz «Expropiación forzosa», Nueva Enciclopedia Jurídica, tomo IX (1958) (pág. 325), Barcelona: Seix, si bien habla enseguida de la consumación de la expropiación para referirse a la final ocupación o toma de posesión; también en la pág. 336 hay otro apunte en la línea de lo que aquí se sostendrá — desconectado, sin embargo, del conjunto del tratamiento que efectúa este autor - cuando se refiere literalmente a «la consumación de la relación que se establece entre la Administración y el expropiado por el pago y la toma de posesión». ¿De qué relación puede hablarse en ese contexto sino de la precisamente creada por un acto jurídico-público anterior, que no puede ser sino el llamado acuerdo de necesidad de ocupación o su equivalente? 
- y pretendió reiterar el proyecto de la Constitución de la I República, de 1873, en su art. 16-, al tiempo que trasladaba la competencia expropiatoria al poder judicial: Nadie podrá ser expropiado de sus bienes sino por causa de utilidad común y en virtud de mandamiento judicial, que no se ejecutará sin previa indemnización regulada por el juez con intervención del interesado.

Tengo para mí que los redactores de la Ley de 1954 no dejaron de pensar más bien en esto o al menos lo intuyeron, lo que explica las determinaciones legales que, como veremos, lo reflejan. Pero no hicieron pronunciamientos explícitos al respecto, por más que ya sea sintomático que no se decidieran a hacerlos, limitándose a establecer las reglas que permiten suponer tal interpretación.

\section{INCIDENCIA DE LA CONSTITUCIÓN DE 1978}

Al desaparecer formalmente con el art. 33.3 de la Constitución, tras no corta discusión parlamentaria, el requisito del previo pago o de la indemnización previa como exigencia constitucional de la expropiación y sustituirse por la fórmula finalmente adoptada - ya usada por el art. 44 de la Constitución de $1931^{5}$ - que requiere simplemente que nadie podrá ser privado de sus bienes y derechos sino [...] mediante la correspondiente indemnización, cambiaron los presupuestos fundamentales. Se fortalecería entonces la tesis de García de Enterría, con la que, agudamente, ya tras la Constitución de 1978, ha tratado de salvar el requisito de la previa indemnización, a pesar de la evidencia de su voluntaria marginación en los acuerdos que prosperaron en las Cortes españolas al adoptarse el citado art. 33.3.

Puesto que la Constitución dice ahora que la expropiación ha de llevarse a cabo mediante la correspondiente indemnización — sostendrá García de Ente-

5 Si bien entonces se añadió su neta relativización: «[...] a menos que disponga otra cosa una ley aprobada por los votos de la mayoría absoluta de las Cortes». Cabe notar, por cierto, que ya la Constitución de 1812, al determinar en su art. 172 «las restricciones de la autoridad del Rey, dice en la décima que, si en algún caso fuere necesario para un objeto de conocida utilidad común tomar la propiedad de un particular, no lo podrá hacer, sin que al mismo tiempo sea indemnizado, y se le dé el buen cambio a bien vista de hombres buenos». En lo que, sin incluir en puridad la indemnización como algo previo o anterior, se percibe, no obstante, el eco de aquel conocido texto de la Partida Segunda (Ley 2a del título I) que decía: «E si por aventura gelo oviesse a tomar, por razón que el Emperador oviesse menester de fazer alguna cosa en ello, que se tornase a pro comunal de la tierra, tenudo es por derecho de le dar antes buen cambio, que vala tanto o mas, de guisa que él finque pagado, a bien vista de omes buenos». 
rría-, resulta obligado entender evidentemente que el acto expropiatorio residirá precisamente en el pago del justiprecio indemnizatorio, sin que quepa traspasar el objeto expropiado al beneficiario hasta que ese pago, y por tanto toda expropiación conforme al art. 33.3 de la Constitución, haya tenido lugar. Sería, pues, el acto, también real, de abono del justiprecio —o de su consignación, conforme a la ley, en los supuestos de litigio sobre el justiprecio- lo que constituiría, en efecto, el acto expropiatorio, cuya ejecución y consumación se lograría con la final toma de posesión ulterior del objeto expropiado. "Observando que la ocupación es simplemente, la traditio en su calidad de modo de adquirir (art. 609 CC), resultará entonces que el verdadero título, en sentido propio, de la atribución patrimonial al beneficiario, o del desapoderamiento del expropiado, cuando esa atribución directa no se produzca, es precisamente el pago de la indemnización ${ }^{6}$. Por eso, en efecto, a su juicio, «la regla del previo pago, en los términos expuestos, continúa teniendo un respaldo constitucional inequívoco»?

Otros autores, en cambio, como Fernández Farreres, aun afirmando, como es común, que «la expropiación es el resultado de un acto administrativo unilateral e imperativo, fruto del ejercicio de la correspondiente potestad $»^{8}$, no dejan de advertir que "con carácter general, la LEF sanciona la regla de que la expropiación (por tanto — dice textualmente este autor- la ocupación y, en su caso, la transferencia de la titularidad del bien) estará precedida del pago de la indemnización»" ${ }^{9}$, que no podrá, por tanto, ser considerado el

6 E. García de Enterría y T.-R. Fernández (2011), Curso de Derecho Administrativo, II, 12a ed. (pág. 289), Cizur Menor (Navarra): Civitas, Thomson-Reuters (igualmente, [2017] 15 a ed., pág. 307). El texto citado se encuentra ya redactado tal cual, sin embargo, antes de la Constitución de 1978, desde 1977, en la 1a ed. de este vol. II de la op. cit., pág. 240, Madrid: Civitas, igual que —además de la interesante conexión con los contratos reales que ya se hace también en las págs. 241-242 de esta $1^{\text {a }}$ ed.— lo que se afirma justo a continuación del texto citado, tras punto y aparte: «Este mecanismo es básico y conduce a calificar la indemnización no como un efecto o consecuencia derivada de la expropiación propiamente dicha, sino justamente como lo contrario, como un presupuesto de legitimidad para el ejercicio de la potestad expropiatoria» ([2011] 12a ed., cit.: 289, [2017] 15a ed.: 307, [1977] 1ª ed.: 240). Una afirmación que, en cambio, no deja de ser contradictoria con lo que se decía en el párrafo precedente, aunque tal vez se tratase entonces de encajar mejor la institución en el marco legal concreto de la Ley de 1954, en el que, como ya hemos advertido, parece que el ejercicio de la potestad expropiatoria solo se produciría precisamente con la ocupación final del objeto expropiado.

(2011) Op. cit., 12a ed. (pág. 291) y (2017) 15ª ed. (pág. 309).

(2016) Sistema..., II, $3^{a}$ ed. cit. (p. 248).

(2016) Op. cit. (pág. 271). 
acto expropiatorio, sino algo previo, aunque «lo cierto es —añadirá el mismo autor- que el art. 33.3 CE no impone el previo pago, al utilizar la expresión «mediante la correspondiente indemnización»» ${ }^{10}$. En esto último suele coincidir la mayor parte de la doctrina ${ }^{11} \mathrm{y}$, además, ha sido así declarado por el Tribunal Constitucional, particularmente en su Sentencia 166/1986, de 19 de diciembre, en el asunto RUMASA ${ }^{12}$.

La realidad es que, salvo la posición de García de Enterría que, como hemos dicho, parece querer aprovechar el art. 33.3 de la Constitución para reafirmar con más contundencia la ya incoada por su parte antes de la Constitución, en la línea de situar el acto expropiatorio específicamente en el pago del justiprecio como auténtico negocio jurídico o acto administrativo real y no formalmente declarativo, puede afirmarse que la cuestión del momento y forma del acto administrativo expropiatorio propiamente dicho sigue estando abierta, sin que se hayan producido propuestas, específicamente fundamentadas, para dar con una respuesta que aclare y dote de plena coherencia a nuestro derecho de la expropiación forzosa. Vamos a intentarlo aquí con algún detenimiento.

10 Ibid. (pág. 272).

11 La nueva expresión constitucional ha efectuado «una configuración del justiprecio simplemente indemnizatoria y sin carácter previo» y "parece ser más una descripción consentida de la realidad existente cuando se dicta la Constitución que una rectificación, por otra parte muy necesaria, de la situación preconstitucional», viene diciendo también R. Parada (2014), Derecho Administrativo, II (Régimen jurídico de la actividad administrativa), 21 a ed. (pág. 483), Madrid: OPEN. La Constitución «omite conscientemente el capital requisito de que la indemnización tenga carácter previo al desapoderamiento del bien (como ya lo hiciera la Constitución de la II República)», afirma por su parte J. A. Santamaría Pastor (2006), Principios de Derecho Administrativo General, II, reimpr. de la $1^{\text {a }}$ ed. (pág. 432), Madrid: Iustel, aunque entiende luego que "salvo en [...] casos singulares [de socializaciones masivas de bienes o recursos], la obligación del previo pago del justiprecio sigue constituyendo la regla general» (ibid: 447). «El art. 33.3 ha suprimido la exigencia de que la indemnización tuviera carácter previo a la materialización de la expropiación», L. Cosculluela (2016), Manual de Derecho Administrativo, 27a ed. (págs. 634-635), Cizur Menor (Navarra): Civitas, Thomson-Reuters. «La legislación en vigor y la propia Constitución han eliminado la exigencia de previo pago en todo caso», escribe M. Sánchez Morón (2010: 730). Lo mismo observa E. Guichot (2014: 186).

12 Lo recuerda, entre otros, G. Fernández Farreres (2016: 272), quien se detiene además en dar cuenta del debate constituyente que "prueba inequívocamente» la voluntad política que llevó a la fórmula mediante y no previa la correspondiente indemnización (ibid.: 273-274). Pero también lo recogen E. García de Enterría y T.-R. Fernández (2011: 291; 2017: 309). 


\section{EL ACTO EXPROPIATORIO COMO «ACUERDO IMPERATIVO» DE «PRIVACIÓN SINGULAR»}

El art. $1^{\circ}$ de la Ley de Expropiación Forzosa define certeramente la expropiación como cualquier forma de privación singular de la propiedad privada o de derechos o intereses patrimoniales legitimos, cualesquiera que fueran las personas o entidades a que pertenezcan, acordada imperativamente, ya implique venta, permuta, censo, arrendamiento, ocupación temporal o mera cesación de su ejercicio.

El acto expropiatorio viene a ser, por tanto, un «acuerdo imperativo» que determina, ordena o impone esa "privación singular», esa ablación de derechos o intereses legítimos patrimoniales, y que puede implicar o equivaler - por el efecto que produce- a una compraventa, una permuta o cualquiera de las otras relaciones o resultados que se mencionan en el precepto ${ }^{13}$.

13 No es momento de detenernos en la comprensión del acto expropiatorio o ablatorio como constitutivo de lo que podría considerarse un contrato forzoso, si el contrato, más que en un tipo determinado de acto jurídico de voluntad acordada entre dos o más sujetos en situación jurídica de igualdad — tan capital en las relaciones jurídico-privadas o en las jurídico-públicas, internacionales o internas, entre sujetos públicos jurídicamente independientes entre sí-, reside sobre todo esencialmente en la naturaleza sinalagmática y recíproca del vínculo obligacional que se constituye entre dos o más sujetos bajo criterios de justicia conmutativa. Bien que excepcionalmente y solo por el poder público, tal tipo de vínculo podría imponerse también por razones justificadas de utilidad pública o interés social. Un joven Díez-Picazo, hace más de sesenta años, en un conocido trabajo, se opuso al uso de la expresión contratos forzosos, proponiendo hablar en cambio de actos jurídicos (públicos) de constitución forzosa de relaciones jurídicas privadas (L. Díez-Picazo y Ponce de León [1956], «Los llamados contratos forzosos», Anuario de Derecho Civil, 1956-1, págs. 112 y ss.), pero precisamente por situar lo esencial del contrato en su nacimiento en el acuerdo libre y voluntario de las partes (op. cit., pág 100), a pesar de reconocer que "contrato — contractus - quiere, según su prístino y etimológico valor, decir «lo contraído». Lo contraído es la obligación —ob-ligatio —; es decir, un vínculo, una relación» (pág. 103), recordando en la nota 63, a propósito de los orígenes de la noción de contrato en el derecho romano, que «sólo en el Derecho justinianeo el contrato significa el acuerdo de voluntades», y cita al efecto Inst. 3, 13, 2.

Hace años que venimos razonando la necesidad de centrar la esencialidad del contrato en la modalidad relacional o de vínculo en que consiste - en el contrato in facto essey no en el tipo de acto que lo genera o constituye - el contrato in fieri- como condición de una teoría propiamente general del contrato que pueda ser aplicable tanto en el derecho privado como en el público. Véanse nuestros estudios «Naturaleza de los contratos públicos a la luz del Derecho español, su fundamento y sus consecuencias», 
Si la noción de expropiación alude en sí misma sobre todo a la realidad, en efecto, de una pérdida de la propiedad o de lo que es propio, a la mencionada "privación singular», en suma, de un derecho o interés patrimonial ${ }^{14}$, se entiende que solo se considere efectivamente producida con lo que la propia Ley de Expropiación llama la "toma de posesión» (enunciado del cap. IV del título II) o la "ocupación de la finca» expropiada o el «hacer ejercicio del derecho expropiado» (art. 51), con cuyos actos o actuaciones se consuma la "privación singular» o ablatoria correspondiente. Pero hay que destacar que para que se trate de una expropiación, tal "privación singular» ha de ser o haber sido objeto de un «acuerdo imperativo" por parte del poder público; en nuestro caso, en principio, según la Ley de Expropiación Forzosa y las exigencias propias de la separación constitucional de poderes, por parte de una Ad-

en J. C. Cassagne (dir.) (1998), Derecho Administrativo (obra colectiva en homenaje al profesor Miguel S. Marienhoff) (págs. 947-969), Buenos Aires: Abeledo-Perrot; «La adjudicación», en J. C. Cassagne y E. Rivero Ysern (dirs.) (2006), La contratación pública, 2 (págs. 681-721), Buenos Aires: Hammurabi, «Naturaleza jurídica del contrato público", AA.VV. (2008), La contratación administrativa en España e Iberoamérica (págs. 481-522), Londres: Junta de Castilla y León, Cameron May; y (2011) «El nacimiento de los contratos públicos: reflexiones sobre una equivocada transposición de la Directiva comunitaria "de recursos»», Revista de Administración Pública, 185, págs. 345-363, y en J. M. de la Cuétara Martínez, J. L. Martínez López-Muñiz y F. Villar Rojas (coords.) (2011), Derecho administrativo y Regulación económica (Liber amicorum Gaspar Ariño Ortiz) (págs. 339-363), Madrid: La Ley.

14 Nemesio Rodríguez Moro, aun olvidando mencionar el locus de esta fuente, señalaba que Clemente de Diego escribió que «si apropiación (en latín appropiatio, de ad y propriatio) significa el acto de apoderarse de una cosa, de aprehenderla, de entrar en conexión y contacto con ella, estableciendo la relación de propiedad que, al ser disciplinada por el Derecho objetivo, se desdobla en facultades y atribuciones de goce y disposición para el titular, para el dueño, y en deberes de abstención y respeto para los demás; expropiación (de las latinas ex, fuera, y propriatio) significa la extinción de esa relación, la decadencia de ese poder y anulación de esas facultades y atribuciones. Apropiación es ocupación y toma de posesión con el alcance en su caso de adquisición del dominio; expropiación es desposesión, pérdida, privación o extinción del domino» ([1958] voz «Expropiación forzosa», cit., pág. 321, nota 1). García de Enterría ya había observado antes que la "privación» en que la expropiación consiste «es, en el genuino sentido de la expresión, un despojo (término de filiación etimológica común con "expropiación")», algo bien distinto de una "limitación», "que es un límite inmanente e intrínseco a la propiedad y a todos los derechos» [(1956) Los principios de la nueva Ley de Expropiación Forzosa (Potestad expropiatoria, garantía patrimonial, responsabilidad civil de la Administración) (pág. 73), Madrid: IEP; (2006) 2a reimpr. Facsímil (pág. 73), Madrid: Civitas, Thomson]. 
ministración pública (además, de suyo, territorial). La privación del derecho o interés patrimonial legítimo que la expropiación produce requiere, pues, que sea dispuesta imperativamente por un acto administrativo declarativo de voluntad, plenamente intencional ${ }^{15}$, resolutorio, un acto formal de imperio. Es este acto, por tanto, el que es propiamente expropiatorio, en cuanto es el que decide y ordena imperativamente esa privación de conformidad con la ley, por decirlo empleando términos del art. 33.3 de la Constitución. La "toma de posesión», la "ocupación» o el inicio del ejercicio del derecho expropiado por parte del beneficiario son solamente consumación o ejecución de lo decidido y dispuesto por la Administración expropiante en dicho acto, la plasmación fáctica del efecto generado por ese acto expropiatorio. A semejanza de como la entrega o transferencia efectiva del dinero de una subvención no es en realidad el acto jurídico al que llamamos con este nombre sino su ejecución, o la recepción de una obra concluida en virtud de un contrato de obras no es, desde luego, este contrato y menos aún su adjudicación constitutiva, sino parte sustantiva de su ejecución o consumación, o, en fin, lo mismo que el embargo de un bien debe diferenciarse de la orden administrativa de apremio sobre el patrimonio de quien figura como deudor de la Administración y que es la causante inmediata del derecho de esta a la entrada en posesión del bien embargado con vistas a la satisfacción de la deuda correspondiente.

Nuestra tradición jurídica está acostumbrada a diferenciar, en la transmisión de bienes y derechos, entre el título y el modo ${ }^{16}$. El título genera el vínculo translaticio y los correspondientes derechos y obligaciones relativos a la trasla-

15 Sobre este concepto, véase M. Caetano (1946), Tratado elemental de Derecho administrativo (Teoría General), tr. y notas de L. López Rodó (pág. 250), Santiago de Compostela: Sucesores de "Galí». La expresión nos parece más certera que la de acto negocial o acto negocio jurídico, que, desde la recepción sobre todo de Kormann, ha tendido a prevalecer en Espańa, véase F. Garrido Falla, Tratado de Derecho administrativo, I (Parte General), desde su $1^{\mathrm{a}}$ ed. (1958) (págs. 401 y ss.), Madrid: IEP, y, antes, A. Royo-Villanova (1955), Elementos de Derecho administrativo, 24a ed. corr. y aum. por Segismundo Royo-Villanova (págs. 210-101), Valladolid: Santarén.

16 Véase J. L. Lacruz Berdejo (2008), Nociones de Derecho Civil Patrimonial e Introducción al Derecho, 6a ed. rev. y puesta al día por J. Delgado Echevarría y Ma A. Parra Lucán (págs. 131-132), Madrid: Dykinson, y, más ampliamente, J. L. Lacruz Berdejo, F. Sancho Rebullida, A. Luna Serrano, J. Delgado Echevarría, F. Rivero Hernández y J. Rams Albesa (2003), Elementos de Derecho Civil, III, Derechos Reales, vol. $1^{\circ}$ (Posesión y propiedad), 2a ed., rev. y puesta al día por A. Luna Serrano (págs. 99-101 y 175-194), Madrid: Dykinson; o L. Díez-Picazo y A. Gullón (2016), Sistema de Derecho Civil, III (I), Derechos Reales en general. Posesión. Propiedad. El Registro de la Propiedad, 9a ed. (págs. 52-61), Madrid: Tecnos. 
ción o transmisión intersubjetiva del objeto jurídico de que se trate, pero esta no se produce o consuma hasta que, en cumplimiento de la correspondiente obligación y para satisfacer el consiguiente derecho, previo cumplimiento, en su caso, también de las obligaciones y satisfacción de los derechos que los condicionen, se lleva a cabo, del modo establecido, la efectiva traslación práctica del objeto de que se trate. ¿Es el modo, la toma de posesión, la ocupación, la traditio o traslación efectiva, importante? Sin duda, imprescindible. Pero su razón de ser y su legitimidad traslaticia se encuentran en el título, que es lo que genera o produce el cambio en derecho que se materializará con el modo. La simple entrega de un bien de una persona a otra o la ocupación por una de un bien de otra son actos que carecen de sentido jurídico en sí mismos, o, por mejor decir, pueden tener una pluralidad de sentidos, significaciones o fines. Lo importante será saber si eso se hace en virtud de una expropiación, de una compraventa o de otro acto jurídico que pueda legitimarlo y darlo sentido, o si, por el contrario, se basa en actos ilícitos o se trata, en suma, de una inmisión o invasión ilegítima e incluso, quizás, punible. Lo determinante será, pues, el acto jurídico del que derivan las actuaciones en que pueda traducirse el inicio de lo que parece una traslación posesoria o de ejercicio de una titularidad jurídica. Nunquam nuda traditio transfert dominium, sed ita si venditio, aut aliqua justa causa praecesserit, propter quam traditio sequeretur ${ }^{17}$. De ahí, en suma, la trascendencia de lo que llamamos el acto expropiatorio, el «acuerdo imperativo» de la "privación singular» que se producirá como consecuencia.

\section{EL ACTO EXPROPIATORIO DEBE IDENTIFICARSE MÁS PLENA Y COHERENTEMENTE CON EL ACUERDO DE NECESIDAD DE OCUPACIÓN DE LA LEY DE EXPROPIACIÓN}

En la regulación contenida en la Ley de Expropiación de 1954 - y lo podríamos decir también análogamente de las regulaciones que la precedieron-, el «acuerdo imperativo» expropiatorio viene a identificarse en realidad con lo que esta Ley denomina el acuerdo de necesidad de ocupación (arts. 21.1 y 22.1), acuerdo por el que se declara la necesidad de ocupación de bienes o adquisición de derechos expropiables (art. 25.1), o, en fin, resolución sobre la necesidad concreta de ocupar los bienes o adquirir los derechos que sean estrictamente indispensables para el fin de la expropiación (art. 15) o sobre la necesidad de la ocupación (art. 20).

17 Atribuido a Paulo en el Digesto, 41, 1, 31, cit. en J. L. Lacruz Berdejo et al. (2003: 175). También aluden a este texto L. Díez-Picazo y A. Gullón (2016: 55). 
Es verdad que el texto de la Ley de 1954 incurre en incorrecciones de expresión que pueden dificultar la comprensión de la realidad, como cuando el art. 21 afirma que el acuerdo de necesidad de ocupación inicia el expediente expropiatorio. ¿Cómo va a ser tal acuerdo o resolución el acto expropiatorio — cabrá así objetar- si solamente constituye el inicio del procedimiento expropiatorio?

Sin embargo, es muy indicativo que, en virtud del art. 36.1, las tasaciones se efectuarán con arreglo al valor que tengan los bienes o derechos expropiables a tiempo de iniciarse el expediente de justiprecio, lo que, por lo que acabamos de ver, coincide precisamente con el acuerdo de necesidad de ocupación. ¿Por qué ha de justipreciarse el objeto expropiado con referencia a la fecha del acuerdo de necesidad de ocupación o a aquella en que este se publique o se notifique debidamente conforme a las previsiones del art. 21.2, si, como es lógico, tal publicación o tal notificación resulta necesaria para que tal acuerdo produzca efectos, de acuerdo con las reglas generales hoy contenidas en la Ley 39/2015, del Procedimiento Administrativo Común, arts. 38 y ss.? Pues, sin duda, porque es ese acto administrativo el que traba o grava el objeto de que se trata, constituyendo ya sobre él el derecho del beneficiario a la adquisición traslativa ${ }^{18}$ del derecho expropiado y la correspondiente obligación del expro-

18 Se ha llegado a decir que la adquisición mediante expropiación «ha de entenderse originaria», que "no es derivativa» (N. Rodríguez Moro [1958], voz «Expropiación forzosa», cit. supra, pág. 322), o — más recientemente- que es «en cierto modo originaria, en tanto que el expropiante o beneficiario no trae causa de quien pierde la titularidad, sino que la razón de ser de la adquisición está constituida por el ejercicio de la potestad pública», L. Y. Montañés Castillo (2017), «La expropiación: concepto, elementos y procedimiento", lección 8 de M. Rebollo Puig y D. J. Vera Jurado (dirs.), Derecho administrativo, tomo III (M. López Benítez y M. Izquierdo Carrasco, coords., Modos y medios de la actividad administrativa (pág. 262), Madrid: Tecnos) pero coinciden más bien en lo contrario el común de los civilistas cuando sistematizan los modos de adquirir la propiedad. De hecho, el art. 8 de la Ley de 1954, aunque afirma que la cosa expropiada se adquirirá libre de cargas, no deja de añadir que, sin embargo, podrá conservarse algún derecho real sobre el objeto expropiado, si resultase compatible con el nuevo destino que haya de darse al mismo y existiera acuerdo entre el expropiante y el titular del derecho. La expropiación puede tener por objeto no solo el derecho dominical sino cualquier otro derecho patrimonial también, incluyendo los inherentes a las cargas que pudieran gravar un bien. Lo más frecuente será ciertamente, cuando la expropiación tenga por objeto la propiedad sobre un bien, que, para poder servir adecuadamente a la finalidad de utilidad pública o interés social, deban expropiarse a la vez los derechos de terceros que recaigan sobre el mismo bien, sean reales o incluso personales o de crédito, como los propios del arrendamiento. Pero nada de esto tiene por qué contradecir el carácter traslaticio del efecto expropiatorio y la naturaleza derivativa de la adquisición de los 
piado a su traditio o a la cesión efectiva de ese derecho - o/y de los intereses patrimoniales legítimos eventualmente en presencia-, aunque la realización o ejecución efectiva de todo ello se produzca más tarde, e incluso, de ordinario, previa tasación y pago del precio o justa indemnización de ese derecho, de conformidad con las previsiones legales.

Precisamente por el efecto expropiante del acto mismo por el que se acuerda o resuelve la necesidad de ocupación, la Ley trata de garantizar que no se demore el pago de la justa indemnización a que obliga la propia Constitución, en su art. 33.3, como requisito ineludible basado en la igualdad de las personas y ciudadanos ante las cargas públicas ${ }^{19}$. Una vez que se decide expropiar un determinado derecho de alguien, debe procederse con la mayor diligencia posible a su tasación y pago, sin someter a su titular a la carga de tener que padecer las consecuencias de dicha expropiación, aunque de momento - en tanto no se consume de manera efectiva- no sean más que las inherentes a la sujeción de su derecho e intereses a la obligación de transmitirlo de manera efectiva al beneficiarlo - o de cesar en su ejercicio en beneficio de este-, con cuanto comporta de limitación sobre su capacidad y libertad de disponer sobre tal derecho y también de usar y disfrutar de él. Tal es la razón por la que el art. 56 de la Ley obliga a la Administración expropiante a abonar al expropiado una indemnización consistente en el interés legal del justiprecio que finalmente se fije, cuando sea culpable de que la determinación del justiprecio por resolución administrativa definitiva se demore más allá de seis meses desde la iniciación legal del expediente expropiatorio, lo que ya hemos dicho coincide con el acuerdo de necesidad de ocupación correspondiente (o su publicación o notificación en cuanto condicionen su eficacia, e incluso con su firmeza, como en realidad viene a reconocer implícitamente el art. $\left.25^{20}\right)$. Y

derechos expropiados por parte del beneficiario. Lo mismo que, si el sujeto que se toma por expropiado resulta distinto del que tuviera su derecho inscrito en el Registro de la Propiedad y no fuese el verdadero propietario o titular del derecho expropiado - a lo que se refiere expresamente el autor citado-, el que no por ello la expropiación dejase de producir su efecto la convierte en adquisición originaria, con independencia de los efectos, en su caso, incluso invalidantes, que pudiera traer consigo tal error, de haberse incumplido requisitos procedimentales legales.

19 Señalaba expresamente el papel determinante de este principio Nemesio Rodríguez Moro en su estudio citado de 1958 sobre la voz «Expropiación forzosa», pág. 321, y lo reitera, citando a Duez, en la pág. 325.

20 Sobre el problema de las discordancias normativas en cuanto al momento de la eficacia de lo que aquí consideramos el acto expropiatorio, véase M. Fuertes López, en F. Sosa Wagner (dir./coord.) (1999), Comentarios a la Ley de Expropiación Forzosa, 2a ed. (págs. 223-228), Cizur Menor (Navarra): Thomson-Aranzadi. 
tal es asimismo la razón por la que el art. 57 impone además una obligación similar de abono del interés legal del justo precio fijado hasta que se proceda a su pago, desde el momento en que hayan transcurrido los seis meses para su pago desde la determinación del justo precio (en vía administrativa) a que se refiere el art. 48: a través de la vinculación de la determinación del justo precio con el momento del acuerdo de la necesidad de ocupación, esta otra garantía contra la indebida demora, no deja de vincularse también finalmente a dicho acto.

Forma parte de la ambigüedad de la Ley, que habría que corregir, que la Ley, al regular en los arts. 25 y ss. el procedimiento de determinación del justiprecio, hable aún de derechos expropiables (arts. 25, 26.2 y 36) o del bien concreto que haya de expropiarse (art. 26.1) o de los titulos que hubiesen de expropiarse (art. 28), como si, cuando se tramita ese procedimiento, el objeto de la expropiación no hubiera sido ya expropiado sino que estaría en camino de llegar a serlo. Aunque otras veces el texto de la Ley en esa misma regulación se refiere más correctamente a los bienes o derechos objeto de expropiación (arts. 24), de la expropiación (arts. 26.2, 28, 30.2, 34 y 43.1) o que se expropian (art. 29.1 ), o incluso en algún precepto los menciona expresamente como derechos expropiados (art. 43.3), lo que solamente puede ser dicho de aquellos que, obviamente, se consideren ya tales, precisamente en virtud del acuerdo de necesidad de ocupación que los haya pormenorizado.

Impropio y contradictorio resulta también que la Ley, que regula en su título II el procedimiento general expropiatorio, articulándolo aparentemente - tras dejar claro en cualquier caso que la declaración de utilidad pública o interés social es un requisito previo indispensable, como dice el art. 9- en las tres fases procedimentales distintas que ya hemos señalado, se refiera luego en varias ocasiones solo a la segunda fase, al procedimiento de fijación del justiprecio como el procedimiento o el expediente expropiatorio, significando con ello una identificación exclusiva con esa segunda fase que dejaría absurdamente fuera, desde luego, la fase procedimental anterior conducente al acuerdo de necesidad de ocupación y hasta quizás la tercera fase sobre el pago y la toma de posesión. Es lo que ocurre con el ya citado art. 21.1 cuando afirma que el acuerdo de necesidad de ocupación inicia el expediente expropiatorio, o con el 36.2, que se refiere a la incoación del expediente de expropiación, o, en fin, con el art. 56, que habla de la iniciación legal del expediente expropiatorio, en lugar de llamarlo, como correctamente hacen, en cambio, los arts. 31 o 36.1, expediente de justiprecio.

Se observará, por otro lado, que el art. 126 habla de la resolución administrativa que ponga fin al expediente de expropiación o a cualquiera de las piezas separadas, para disponer que contra ella se podrá interponer recurso contenciosoadministrativo, con excepción del caso previsto en el núm. 3 del art. 22. La literalidad de la redacción de este precepto resulta críptica. ¿Qué está entendiendo 
ahí la Ley por expediente de expropiación? ¿El conjunto del procedimiento regulado en el título II de la Ley? :Qué resolución administrativa le pone fin entonces? ¿Una orden administrativa de ocupación o de toma de posesión de los bienes o derechos expropiados? No habla la Ley de ella, sino solamente, en el art. 51, del hecho de ocuparse la finca o hacer ejercicio del derecho expropiado, aunque es cierto que no deja de aludirse a que se hará por vía administrativa, lo que comportaría una remisión al régimen general de la actuación fáctica de la Administración, sometida al principio de juridicidad que, con arreglo al art. 97 de la Ley 39/2015, la condiciona a la previa adopción de una resolución que le sirva de fundamento jurídico, que ha de notificarse al expropiado. ¿Está pensando en esta resolución el art. 126 de la Ley de Expropiación? La mención simultánea de las piezas separadas pudiera inclinar a pensar, sin embargo, que se está refiriendo a la resolución de la Administración expropiante o del jurado competente que concluya definitivamente el expediente de justiprecio, que resultaría así mal llamado, una vez más, expediente de expropiación. La Ley, en efecto, solo da el nombre de piezas separadas a los distintos expedientes individuales que el art. 26 ordena abrir a cada expropiado (salvo cuando se trata de un objeto expropiado que pertenezca en comunidad a varias personas o cuando varios bienes constituyan una unidad económica) para proceder a la determinación del justo precio, lógicamente cuando se trata de una expropiación de varios y no de uno solo, lo que, en definitiva, comporta una precisión sobre la modalidad que pueda revestir el propio expediente de justiprecio al que dicho art. 126 se estaría entonces refiriendo. Pero esta lectura encaja a su vez mal con que, a continuación, el apdo. 2 del mismo art. 126, comience diciendo, como si se tratara de algo distinto, que asimismo ambas partes podrán interponer recurso contencioso-administrativo contra los acuerdos que sobre el justo precio se adopten. ¿No sería en realidad esto lo mismo que recurrir contra las resoluciones que pongan fin al expediente de justiprecio o a sus piezas separadas de que se habla en el apdo. 1?

Por otro lado, si el redactor del mencionado art. 126, en su apdo. 1, se sintió precisado — no poco paradójica y sorprendentemente- a excepcionar del recurso contencioso-administrativo a que se está refiriendo, el caso previsto en el núm. 3 del art. 22, es decir, ni más ni menos que la resolución administrativa sobre la necesidad de ocupación que pusiera fin a la vía administrativa — que ya ese mismo art. 22.3 excluía expresamente de la vía contenciosoadministrativa, por más que hace tiempo se venga considerando derogado, lo mismo que la excepción del 126.1 que comentamos ${ }^{21}$ — quiere decir que la

21 Aunque ya antes de la Constitución de 1978 se sostuvo su inaplicación, se ha invocado luego principalmente el efecto derogatorio del art. 24 de la Constitución —con su 
resolución o resoluciones a que se estaría queriendo referir el art. 126.1 para garantizar frente a ellas el control jurisdiccional contencioso-administrativo serían cualquiera de las adoptables en el procedimiento expropiatorio, en su más amplia significación, en cuanto decidieran con efectos definitivos, cerrando en suma cualquiera de las tres fases que la Ley distingue en el procedimiento general. Las piezas separadas de las que habla el precepto habrían de ser entonces también cada uno de esos tramos distintos procedimentales. Es efectivamente usual en la doctrina hablar de fases o piezas separadas para referirse a esos diversos tramos ${ }^{22}$. En cualquier caso, y menos aún en esta hipótesis, el uso por dicho precepto de la expresión expediente de expropiación difícilmente podría identificarse en puridad solamente con el expediente de justiprecio.

Por lo demás, llama la atención —aunque tiene su lógica- que, cuando el art. 125 concreta los supuestos en que, tratándose de privaciones singulares como las que son propias de la expropiación, estaríamos ante lo que nuestra legislación administrativa general — ahora el art. 105 de la Ley 39/2015considera una actuación administrativa por vía de hecho por llevarse a cabo sin seguirse el procedimiento legalmente establecido o, más bien — por decirlo con los términos con los que el ahora art. 47.1.e) de la misma Ley general básica determina su nulidad de pleno derecho- prescindiendo total y absolutamente del procedimiento legalmente establecido, admitiendo excepcionalmente contra ella las acciones posesorias o interdictos, no se hace mención explícita alguna de la determinación del justo precio ni de la tramitación del expediente necesario para ello, cifrándose solamente en no haberse cumplido los requisitos sustanciales de declaración de utilidad pública o interés social — que ya recordamos es una exigencia previa a la posibilidad misma de expropiar-, necesidad de ocupación y previo pago o depósito, según proceda, en los términos establecidos en esta ley. Lo que confirma que el procedimiento expropiatorio, en su sentido más amplio, tiene componentes mucho más sustanciales que la determinación del justiprecio, que, por lo demás, no puede ser en ningún caso sino solo un tramo, una

garantía del derecho a la tutela judicial efectiva-y de su art. 106. Véanse referencias a la doctrina y la jurisprudencia preconstitucionales y a la jurisprudencia postconstitucional en V. Escuín Palop (1999), Comentarios a la Ley de Expropiación Forzosa (págs. 195 a 198), Madrid: Civitas [(2008), 3a ed. (págs. 246 a 250), Cizur Menor (Navarra): Civitas, Thomson-Reuters, con ya alguna sentencia de los 2000 como la STS de 13 de febrero de 2003]; más recientemente y con jurisprudencia también de los 2000, S. Muñoz Machado (2015), Tratado de Derecho Administrativo y Derecho Público General, tomo XIV (La actividad regulatoria de la Administración) (págs. 403404), Madrid: BOE.

22 Cfr. E. García de Enterría, y T.-R. Fernández (2017: 284). 
fase o una parte de dicho procedimiento, evidenciándose la ambigüedad o el error de denominar al expediente o procedimiento de justiprecio expediente o procedimiento de la expropiación, con la apariencia de identificación que ello produce.

Es palmaria, en fin, la función puramente instrumental y secundaria —aun con toda su importancia práctica- de la determinación del justiprecio, cuya única razón de ser mira, en efecto, al cumplimiento de la condición constitucional y legal de toda expropiación, que no es sino la de que no se produzca de modo efectivo la privación o sacrificio individualizado en que se traduce o a que conduce, sin su correspondiente justa indemnización, en principio, además, como exige la Ley salvo excepción legalmente prevista, con carácter previo a tal efectividad. Pero el acto de fijar definitivamente el precio o valor del objeto expropiado requiere la predeterminación, obviamente de este, y, desde luego, en modo alguno comporta en sí mismo una decisión imperativa de privar de su derecho sobre él a quien sea su titular. Esa decisión es anterior y es cabalmente para poder hacerla efectiva por lo que se procede a la tasación de lo que, en realidad, ya ha sido declarado objeto expropiado. La determinación del justiprecio es, en rigor, un acto ejecutivo de la decisión expropiatoria necesariamente previa, de la que procede tanto el derecho al pago - previo, en principio, a la ocupación efectiva y sin demoras- del precio de lo expropiado - que para ello ha de ser debidamente tasado- como el derecho del beneficiario a la recepción o traditio efectiva del objeto expropiado mediante el ejercicio por parte de la Administración expropiante de su potestad pública para ejecutar y consumar la expropiación.

El sistema ganaría en claridad y coherencia si se estableciese claramente como acto expropiatorio, resolución o acuerdo de determinación imperativa de la expropiación, lo que actualmente se denomina acuerdo o resolución sobre la necesidad de ocupación del objeto de la expropiación. Debería quedar más netamente establecido que con ese acto administrativo la Administración expropiante, en ejercicio de la potestad expropiatoria, determina que ciertos bienes o derechos - $\mathrm{e}$ incluso intereses patrimoniales legítimos, en su caso-, de los que sean titulares determinadas personas, deben ser transferidos al beneficiario que se indique o cesarse en su ejercicio, de ordinario previo el pago a sus titulares del justo precio o el abono de la correspondiente indemnización que se fijen conforme a la ley, por ser necesarios de manera indispensable para la finalidad de utilidad pública o de interés social de que en cada caso se trate $^{23}$. Así quedaría indubitablemente configurado como el verdadero acto

23 Cabe observar que el propio García de Enterría, en su citada obra conjunta con TomásRamón Fernández, estructura el tratamiento de la expropiación forzosa en dos capí- 
expropiatorio, con cuantas implicaciones y consecuencias ello habría de comportar, también cara a su eventual revocación total o parcial (modificación) en la medida que el ordenamiento pueda permitirlo con las debidas garantías ${ }^{24}$, y, por supuesto, a su posible anulación en vía administrativa o jurisdiccional por infracción del ordenamiento jurídico.

Es de notar que, cuando el profesor García de Enterría escribió su memorable libro sobre Los principios de la nueva Ley de Expropiación Forzosa de 1956, observó atinadamente que «al decir la Ley que comentamos que la privación de que se trata ha de ser "acordada imperativamente", nos ofrece un nuevo matiz del concepto legal de expropiación. Ha de tratarse de una privación deliberada y querida, producto, por consiguiente —nótese bien, subrayamos nosotros - , de un acto administrativo declaratorio, más explícitamente de un negocio jurídico, caracterizable típicamente entre los negocios de gravamen o que tienden a la restricción de la esfera de los derechos del destinatario ${ }^{25}$. Ciertamente, como venimos diciendo, la privación de que se trata ha de ser "producto», efecto o consecuencia del acto administrativo declaratorio expropiatorio, por más que su ejecución o su consumación requiera el pago de la indemnización y un acto material de ocupación o toma de posesión, de traditio.

Es lástima que esta clara afirmación del ilustre maestro quedara luego más o menos marginada, sin propiciarse los coherentes desarrollos y aplicaciones normativas que implica. Debería irse a una neta identificación, en suma, del acto expropiatorio y de las adecuadas garantías en su adopción, que hoy ya se contemplan sucintamente en la regulación de la elaboración del acuerdo sobre la necesidad de ocupación (arts. 15 a 23). El procedimiento expropiatorio propiamente dicho sería en rigor solamente el conducente a dicho acto. Luego, debidamente diferenciados, estarían los procedimientos para el cumpli-

tulos, dedicando el primero a la potestad expropiatoria, de cuyo ejercicio y su concreción sobre bienes determinados se ocupa más en concreto en su apartado VII, para hablar precisamente de la declaración de necesidad de ocupación, y, luego, el segundo, a la garantía patrimonial en la expropiación, que es donde se ocupa de la determinación y pago del justiprecio (2017: 235 y ss. —más en particular págs. 283 y ss.—y 295 y ss.). Puede verse F. Hervás Vercher (1992), "Algunas cuestiones acerca del desistimiento de la expropiación forzosa (estudio jurisprudencial)», en Expropiación Forzosa, Cuadernos de Derecho Judicial (págs. 153-169), Madrid: CGPJ. Lo que el autor llama desistimiento por situar la expropiación en la toma de posesión, se traduce — siguiendo a Carretero- en revocación del acuerdo de necesidad de ocupación o de lo que tiene valor equivalente (pág. 155).

25 Op. cit. (reimpr. de 2006), pág. 77. La coma entre las palabras «declaratorio» y «más explícitamente» no figura en el texto, suponemos que por errata inadvertida. 
miento o ejecución de la expropiación: tanto el relativo a la determinación del justo precio como el referente a su pago y a la consumación de la expropiación mediante la ocupación del bien, la traslación al beneficiario o el comienzo del ejercicio por este del derecho expropiado, o, en fin, la cesación del expropiado en el ejercicio del derecho expropiado. Serían estas piezas componentes, si se quiere, del procedimiento expropiatorio en su acepción más lata, pero en rigor solo procedimientos para la ejecución de expropiaciones, a seguir, por tanto, en orden a la efectividad de expropiaciones ya «acordadas».

\section{NATURALEZA ADMINISTRATIVA DEL ACTO EXPROPIATORIO}

De la propia afirmación contenida en el art. 33.3 de la Constitución, de que la expropiación ha de hacerse de conformidad con lo dispuesto por las leyes, cabría ya desprender, desde luego, que el acto expropiatorio habrá de ser un acto administrativo, dictado en aplicación de un orden normativo predeterminado principalmente en las leyes (dada además la reserva de ley del art. 53.1 de la misma Constitución), si no fuera suficiente tener en cuenta que, por su propia naturaleza, tendrá siempre por objeto derechos e intereses legítimos concretos y de sujetos determinados, considerados en su singularidad individual, lo que, mientras no se traduzca en supuesto propiamente litigioso que reclame la correspondiente tutela judicial efectiva objeto del derecho fundamental del art. 24. de la Constitución, reservada en nuestro Estado de derecho al poder judicial en los términos del art. 117, no puede ser lógicamente, bajo la separación de poderes, esencial a ese mismo Estado de derecho, sino competencia de las Administraciones públicas debidamente habilitadas para ello.

Esta naturaleza administrativa del acto expropiatorio en el derecho actual — desde luego en el español— no impide, sin embargo, que pueda hablarse también, aun excepcionalmente, de expropiaciones legislativas, pero solo cuando el efecto privativo o ablatorio de derechos determinados de sujetos determinados — que debe contar asimismo con la suficiente indemnización para no infringir el art. 33.3 de la Constitución - se derive directamente de un cambio normativo general, y pueda reconocerse efectivamente como verdaderamente ablatorio, distinto de una nueva delimitación legítima de derechos. El Tribunal Constitucional ha tratado de aclararlo en el caso de la Ley de Aguas de 1985 con relación a su nueva regulación de las concesiones hidráulicas y su general demanialización de las aguas subterráneas y de su captaciones ${ }^{26}$, o cuando la

26 Véase la STC 227/1988, de 29 de noviembre, principalmente FFJ 11 y 12, en relación con las disposiciones transitorias $1^{\text {a }}$ a $4^{\text {a }}$ de la Ley de Aguas 29/1985, que siguen como 
Ley de Costas de 1988 hizo una nueva determinación del alcance del dominio público marítimo-terrestre en aplicación del art. 132.2 de la Constitución ${ }^{27}$. En tales supuestos, de tratarse de una verdadera expropiación ope legis, podrá ocurrir que la misma ley establezca la compensación indemnizatoria constitucionalmente exigible mediante conversión del derecho expropiado en otro de valor económico similar «suficiente», cualesquiera que sean los sujetos expropiados, o bien será imprescindible una actuación administrativa ulterior que aplique en concreto a los expropiados la necesaria compensación indemnizatoria, lo que requerirá comenzar con su identificación si la ley expropiatoria no individualiza a los expropiados, completando en consecuencia en vía administrativa un requisito normalmente esencial de todo acto expropiatorio. Habrá que ver en cada caso cómo se formula la ley expropiatoria, pero es bien posible que no sea en rigor tal, aunque pueda contener un mandato de procederse a la expropiación de bienes o derechos determinados - sin limitarse la ley a declarar determinados fines como de utilidad pública o interés social一, que, luego, sin embargo, habrá de llevarse a cabo en vía administrativa.

Que, fuera de tales supuestos y con esas condiciones, puedan llevarse a cabo por ley actos específica y directamente expropiatorios de bienes o derechos de sujetos determinados, es algo que debería ser rotundamente rechaza$\mathrm{do}^{28}$, a pesar del famoso asunto RUMASA, que, además, se llevó a cabo por Real Decreto Ley — lo que sería aún menos aceptable ${ }^{29}$ —, máxime cuando el Tribunal Constitucional viene rechazando ya la constitucionalidad del revestimiento como leyes formales de actos de suyo propiamente administrativos, aunque lo haya hecho en relación con leyes autonómicas, aceptando los argumentos de supresión o reducción de garantías propias del necesario proce-

tales, con la $3^{a}$ bis añadida después, en el texto refundido aprobado por Real Decreto Legislativo 1/2001, de 20 de julio.

27 Véase STC 149/1991, de 4 de julio, FJ 8 B) en relación con la disposición transitoria $1^{\text {a }}$ de la Ley 22/1988.

28 Véase al respecto R. Parada (2014: 469 y ss.).

29 Se recordará que la STC 111/1983, de 2 de diciembre salvó in extremis la constitucionalidad del Real Decreto Ley 2/1983, de 23 de febrero, gracias al voto de calidad de su entonces presidente, el magistrado Manuel García-Pelayo y Alonso, porque votó en contra la mitad del Tribunal justificándolo en un voto particular firmado por los magistrados Gloria Begué Cantón, Angel Escudero del Corral, Rafael Gómez-Ferrer Morant, Francisco Pera Verdaguer, Francisco Rubio Llorente y Antonio Truyol Serra. El argumento central de este voto disidente radicó en el límite neto que marca el art. 86.1 de la Constitución a los Decretos-Leyes que no podrán afectar a los derechos, deberes y libertades de los ciudadanos regulados en el Titulo I, entre los cuales se incluye palmariamente el derecho a la propiedad del art. 33. 
dimiento administrativo (previa audiencia: art. 105 de la Constitución) y de supresión del derecho a la tutela judicial efectiva que ello comporta ${ }^{30}$.

Con todo, el Tribunal Constitucional no deja de seguir considerando constitucionalmente admisible la posibilidad de leyes singulares expropiatorias - que incluyan directamente la declaración de la necesidad de ocupación, por tanto, de determinados bienes o derechos singularizados-, aun "constreńidas a supuestos estrictamente excepcionales, frente a los que no resulta posible responder mediante el sistema expropiatorio general contenido en las leyes generales» ${ }^{31}$, si bien, en cualquier caso, tal excepcionalidad solo podrá darse «si la idoneidad de los bienes [o derechos] a expropiar es indiscutible en atención al fin legítimamente perseguido y si la naturaleza misma de esos bienes, su identidad, diversidad o localización convierten en imposible, por insuficiente, el recurso a la simple acción administrativa» ${ }^{32}$.

30 Véase la STC 129/2013, 4 de junio, que, entre otras cosas, en sus FFJJ 5 a 7, asume el fundado parecer del voto particular de Rubio Llorente, al que se adhirió Truyol Serra, contra la STC 166/1986, relativa a la expropiación de RUMASA, centrado en la violación del derecho a la tutela judicial efectiva que produce el acto administrativo con forma de ley. La citada STC 166/1986 había, no obstante, afirmado — como recuerda la misma STC 129/2013 - , que «los derechos fundamentales no consienten, por su propia naturaleza, Leyes singulares que tengan el específico objeto de condicionar o impedir su ejercicio; dichos derechos son materia reservada a Leyes generales y reducto inmune a medidas legislativas singulares» [FJ 11,c)]. Sorprendentemente, sin embargo, el Tribunal no fue entonces consecuente con tan importante y certera afirmación, recuperada con acierto en la citada Sentencia de 2013 (FJ 4). En similar sentido también la STC 203/2013, de 5 de diciembre. El Tribunal llama, por cierto, leyes autoaplicativas a las que "contienen una actividad, típicamente ejecutiva, de aplicación de la norma al caso concreto» (FJ 3 de la sentencia cit. en último lugar).

31 STC 48/2005, de 3 de marzo, FJ 5.

32 STC 48/2005, cit., FJ 6. Y ello porque, como se razona poco antes en ese mismo FJ, «un acto legislativo expropiatorio sólo será constitucionalmente admisible si el control jurisdiccional que admiten las normas con rango de ley (recurso directo, cuestión y autocuestión de inconstitucionalidad; esta última previo amparo) es suficiente, en cada caso, para brindar una tutela materialmente equivalente a la que puede dispensar frente a un acto administrativo un Juez de lo contencioso», de lo que deriva una «necesaria correspondencia entre las posibilidades de defensa de los derechos e intereses legítimos, por un lado, y el instrumentario que para su ejercicio efectivo puede dispensarse en los procedimientos de control de constitucionalidad de la ley, por otro", delimitándose así con ello, en efecto, «el umbral de las circunstancias excepcionales que justifican la figura de la ley expropiatoria singular». 


\section{IMPORTANCIA DE QUE LOS ACTOS EXPROPIATORIOS "IMPLÍCITOS"SE NORMALICEN COMO EXPLÍCITOS Y CON TODAS LAS DEBIDAS GARANTÍAS}

Es sabido que, en la práctica, en la mayor parte de las expropiaciones el acto expropiatorio no se produce en la forma regulada por la Ley de Expropiación de 1954 como parte del procedimiento general expropiatorio sino con la aprobación de proyectos de obras y servicios, aunque solo cuando comprendan la descripción detallada, concreta e individualizada, en todos los aspectos, material y jurídico, de los bienes o derechos cuya expropiación resulte necesaria. A ello se refiere bien expresamente el art. 17 de la Ley de 1954 en su apdo. 2 para afirmar que la necesidad de ocupación se entenderá implícita en dicha aprobación. Y lo repiten, de una u otra manera, no pocas normas legislativas - refiriéndose a proyectos y planes de obras-, que, lógicamente, dada la reserva al Estado establecida en el art. 149.1.18 a de la Constitución, serán estatales, aunque puedan afirmarlo también, recogiendo lo establecido por estas, algunas normas autonómicas ${ }^{33}$.

Siendo estas declaraciones «implícitas» de la necesidad de ocupación las que, en efecto, deciden las expropiaciones actuales en la mayor parte de los ca-

33 Así el art. 94 del TR de las disposiciones legales vigentes en materia de Régimen Local, aprobado por RDLeg 781/1986, que dispone, en efecto, que las obras comprendidas en los planes de obras y servicios locales, incluidos los planes provinciales de cooperación, llevarán aneja la declaración de utilidad pública y la necesidad de ocupación de los terrenos y edificios en ellos comprendidos a efectos de su expropiación forzosa. La legislación sectorial es insistente: art. 130 de la Ley de Aguas — ahora TR aprobado por RDLeg $1 / 2001$ - en cuanto a la aprobación de proyectos de obras hidráulicas de interés general, o art. 45 de la Ley de Costas — Ley 22/1988_- para los proyectos de obras marítimas o costeras que puedan requerir expropiaciones, y el 61 de la Ley de Puertos del Estado y de la Marina Mercante — TR aprobado por RDLeg 2/2011 —, para las obras portuarias; análogamente, el art. 8 de la Ley de Carreteras - Ley 25/1988, en la redacción que a dicho artículo ha dado la Ley 24/2001—, y el 6.2 de la Ley del Sector Ferroviario, Ley $38 / 2015$, para los proyectos de carreteras y obras ferroviarias respectivamente, aunque en ambos ámbitos su aprobación conlleva automáticamente además declaración de urgencia. No cabe olvidar, aun sin pretensiones de exhaustividad, la análoga tradicional previsión, hoy contenida en el art. 42 del TR de la Ley del Suelo y Rehabilitación Urbana, aprobado por RDLeg 7/2015 (que mantiene el texto del 28.2 de la Ley de 2007), relativa a los instrumentos de la ordenación territorial y urbanistica que determine su legislación reguladora [...], cuando [...] habiliten para su ejecución y ésta deba producirse por expropiación (véase doctrina jurisprudencial en J. R. Fernández Torres [2007], Estudio integral de las Expropiaciones Urbanisticas, 2a ed. [págs. $194 \mathrm{y}$ ss.], Cizur Menor: Thomson-Aranzadi). 
sos — con el cortejo además en su caso de los replanteos y reformados a que se refieren algunos textos legales, siguiendo lo expresamente dispuesto por el art. $52.1^{\text {a }}$ de la Ley de 1954 para la expropiación urgente ${ }^{34}$ — es ciertamente decisivo lograr ante ellas las mismas garantías que la Ley de Expropiación dispone para el acuerdo de necesidad de ocupación en su regulación del procedimiento llamado general. La doctrina ya ha llamado la atención al respecto y urgido a la adopción de resueltas medidas legales ${ }^{35}$, y tanto el Tribunal Supremo como el Constitucional han hecho pronunciamientos favorables al mantenimiento de las garantías que deben considerarse irrenunciables ${ }^{36}$.

34 El acto expropiatorio en tales supuestos sufre un desdoblamiento de modo que no quedará completo, respecto a los bienes o derechos que hayan de expropiarse en razón del replanteo o de los reformados, hasta esos actos de replanteo o de aprobación de modificaciones conforme a la ley, de los que, por cierto, podrá derivarse a la vez una revocación parcial del acto expropiatorio inicial inherente a la aprobación del correspondiente proyecto de obras, que habrá de tratarse como tal.

35 Véase E. García de Enterría y T.-R. Fernández (2017: 286-287), S. Muñoz Machado (2015: 401-402), o V. Escuin Palop (2008: 220 y ss.), destacando este los incumplimientos en el ámbito local, con cita de F. Romero Hernández (1974), «Necesidad de ocupación e indefensión de los expropiados en la Administración Local», REVL, 181, págs. 57-70. Afirma también la necesidad de las efectivas garantías J. Huelin Martínez de Velasco (1992), "El procedimiento expropiatorio en general», en Expropiación Forzosa, Cuadernos de Derecho Judicial (págs. 98-99), Madrid: CGPJ. Habla de desnaturalización del acuerdo de la necesidad de ocupación L. Tolivar Alas (1999: 59).

El Tribunal Supremo ha recordado «que la aprobación implícita de la necesidad de ocupación exige la previa información pública y audiencia de los afectados por el proyecto»: cfr. V. Escuin Palop (2008: 220). Lo que se ilustra en primer lugar con la STS de 23 de julio de 2002 (RJ 2002, 8638), que, aunque no se refiere en concreto a la necesidad de previa información pública o de audiencia sino a la exigencia de que el proyecto contenga en todo caso «una descripción no sólo material sino también jurídica de los bienes o derechos a expropias», hace la importante afirmación general de que «estas declaraciones implícitas de necesidad de ocupación por razones de economía burocrática precisan que en ningún caso puedan entrañar menoscabo de las garantías de expropiado» (ibid.); pero también con la STS de 6 de marzo de 1997 (RJ 1997, 2291), que claramente afirma que «la audiencia posterior de los propietarios no es suficiente para subsanar la falta de audiencia previa a la aprobación del proyecto» (ibid.: 220-221), o las de 13 de febrero (RJ 2003, 2842) y 18 de marzo de 2003 (RJ 2003,3217 ), que rechazan la convalidación de lo que fue anulado por omisión de la necesaria previa audiencia (ibid.: 221-222). Menciona además, por otra parte, este mismo autor la STS de 16 de marzo de 2005 (RJ 2005, 4307) (op. cit.: 222-223), relativa a otra garantía, no menos importante, en cuanto que claramente viene a afirmar la obligación de notificar personalmente a los expropiados la declaración implícita de 
Pero la seguridad jurídica aconsejaría comenzar por establecer claramente en la ley que los planes o proyectos de obras de naturaleza propiamente expropiatoria deben declararlo de manera explícita, ajustándose además, por supuesto, a los requisitos de contenido — de determinación individualizada de derechos y sujetos expropiados-, de procedimiento y de ejecución que no deben dejar de imponerse en todo caso.

No es posible ya demorarse aquí en esta importante vertiente. Los particulares deben quedar garantizados también frente a aquellos planes o decisiones que puedan implicar con suficiente probabilidad algún tipo de expropiación, máxime cuando en la práctica se restrinja con ello, aun antes de la expropiación propiamente dicha, el ejercicio de los derechos que a la postre resulten probablemente expropiados. Medidas como la norma conocida en el derecho urbanístico que permite a los sujetos afectados, dentro de determinados plazos y con los debidos requisitos, dar ope legis por producida la expropiación y por iniciado, para su ejecución, el pertinente expediente de fijación del justiprecio, permitiéndose acudir directamente al jurado, u órgano autonómico equivalente, para que lo determine, en caso de pasividad de la Administración expropiante, deben contribuir a esa garantía, afinándose su regulación ${ }^{37}$.

necesidad de ocupación - como ocurre en general con el acuerdo de necesidad de ocupación, según dispone el art. 21.3 de la Ley de Expropiación Forzosa-, de modo que si no se hiciese, no transcurrirán los plazos para impugnarla.

También se ha dicho que el Supremo, con respecto a las prácticas abusivas detectadas en estas llamadas "declaraciones implícitas», "se ha mostrado reticente a aceptarlas incondicionalmente»: S. Muñoz Machado (2015: 401-402), donde cita prácticamente las mismas cuatro primeras sentencias citadas por Escuín, añadiendo otra de 16 de junio de 2004; el mismo texto está (2011) en la edición anterior del mismo Tratado, tomo IV, Madrid: Iustel, pág. 863.

La exigencia firmemente asentada por el Tribunal Constitucional, en la Sentencia $48 / 2005$, sobre la inconstitucionalidad de impedir, mediante expropiación legislativa singular, que quienes puedan resultar expropiados puedan cuestionar justificadamente el carácter necesario o indispensable de sus bienes o derechos para la finalidad de utilidad pública o de interés social de que se trate, bajo las garantías del derecho a la tutela judicial efectiva de los órganos del Poder Judicial, es perfectamente aplicable también a que ello pueda hacerse mediante una expropiación determinada con la aprobación de un proyecto o plan de obras: véase E. García de Enterría, E. y T.-R. Fernández (2011: 269-270; 2017: 287).

37 Aun con regulaciones no enteramente coincidentes, véase TR de la Ley estatal del Suelo de 1976, art. 69, Ley del Suelo de la Comunidad de Madrid 9/2001, art. 94, Ley de Urbanismo de Castilla y León 5/1999, art. 93.6 (y 227 de su Reglamento de 2004), etc. 
